\title{
Electroconvulsive therapy for children
}

To the editor - Tony Baker's commentary, "The minor issues of electroconvulsive therapy," published in the March issue of Nature Medicine (pages 199-200), presents some contradictory arguments and arrives at an unsupported conclusion. The author states: "Electroconvulsive therapy (ECT) is a recognized medical procedure for treating well defined psychiatric illness, whose effectiveness is recognized by professional medical organizations world wide" and "its success in treating mania, catatonia and melancholia has earned it a reputation as something of a lifesaver," then points out several cases in which ECT was administered to children and adolescents for indications other than those generally accepted, and concludes that "ECT should not be used in any child under 16 years of age." This conclusion is unreasonable because it ignores the possibility that children can develop the exact conditions which are indications for ECT in adults, and severely enough so that aggressive intervention is warranted to minimize morbidity and perhaps avoid mortality.

We recently published a case report of a previously high-functioning nine-year old girl with rapid onset of classic depressive symptoms who progressed, in spite of appropriate treatment with antidepressants, hospitalization and psychotherapy, to a catatonic state ${ }^{1}$. Her symptoms included mutism, refusal to eat or drink, severe musculoskeletal rigidity and urinary and fecal incontinence and could have become lifethreatening. This patient was evaluated by three child psychiatrists and two pediatric neurologists, all of whom agreed, after a full organic workup, that ECT was indicated. She received 19 ECT's - a lengthy course, but following accepted parameters for continuation and termination of treatment-and had a full recovery. She has now been out of the hospital for 18 months, lives with her family, attends school where she does well, has friends, and participates in sports.

If ECT had not been available as a treatment option, this young girl may have had a lengthy catatonic episode, with significant physical morbidity and loss of developmental and academic time. As it was, she was able to complete the academic year with her classmates and re-establish social connections quickly and easily.

Conditions that are appropriate indications for ECT are very rare in children. For those rare cases, however, ECT must continue to be available.

1. Cizadlo, B.C. \& Wheaton, A. Case Study: ECT Treatment of a Young Girl with Catatonia. I. American Acad. child adolescent Psychiatry, 34, 332-335 (1995).

Beth C. Cizadlo \& Allyson Wheaton University of Iowa

Department of Psychiatry

200 Hawkins Drive, Room 1882 JPP

Iowa City, Iowa 52242-1057

Baker replies - I am concerned to read of a child of nine years of age being treated with 19 electro-convulsive shocks.Total refusal syndrome is recognized as a rare psychiatric syndrome of childhood which requires a high level of intervention to maintain life if not growth. The aetiology is unknown. The clinical account of severe childhood depression which deteriorated into a catatonia-like state suggests a process of primary or secondary neurotransmitter disturbance. It may also have had its origins in a neurotic (reactive) as opposed to a primarily organic process.

I wonder how many treatments would have been administered before abandoning ECT. ECT has its effect through modifying the neurotransmitter bath in which the brain tissue operates. It is entirely non-selective and may affect every neurological pathway. The child will also have had nineteen anaes- thetic procedures and nineteen episodes of total muscle relaxation.

Cizadlo and Wheaton use that term 'life-threatening' yet they had the power to manage all the child's vital functions. She was not going to die of urinary or fecal incontinence nor of mutism. It is wheeled out as the justification for using a treatment approach that is itself life-threatening and that leaves many people with a long-term experience of being damaged. These wellintentioned doctors took an enormous risk in relation to her short- and longterm memory function. Although the clinical experiment was successful in that it seems to have promoted a recovery process that was completed without detriment to the child, I do not think that the success of the experiment justifies it, nor do I think it should be repeated. Although I would be reassured to an extent if the clinicians involved had used safeguards to ensure that the child received minimal exposure to electric current, I do not think that physical damage to delicate brain tissue is the only issue. People feel damaged psychologically by the process of electroconvulsive therapy. This child may well have amnesia for the clinical experience but at some point the meaning of her treatment may come to be traumatic.

Doctors cannot be sure what works when a treatment such as ECT is used. Neurotransmitter failure is poorly understood. There are other ways of manipulating neurotransmitters and we have an ever-increasing repertoire of psychotropic preparations available to us. I think that we have a responsibility to exhaust those possibilities before we commit vulnerable children to a potentially damaging clinical course.

\section{TONY BAKER}

Ashwood Centre

Ashwood Road,

Woking, Surrey GU22 7JR, UK

\section{LETTERS TO THE EDITOR}

Nature Medicine encourages brief letters to the editor (no more than 500 words) on topics that have been reported in previous issues or on subjects to the biomedical research community.

Letters should be addressed to: Nature Medicine, 1234 National Press Building, Washington, DC 20045. You may also fax (202.628.1609) or e-mail (medicine@naturedc.com) your letter. 